\title{
Active control implementation in cable-stayed bridges for quasi-static loading patterns
}

Article in Engineering Structures · July 2016

Impact Factor: 1.84 · DOI: 10.1016/j.engstruct.2016.03.061

READS

19

2 authors:

Miquel Crusells-Girona

University of California, Berkeley

12 PUBLICATIONS 5 CITATIONS

SEE PROFILE
Angel C. Aparicio

Polytechnic University of Catalonia

64 PUBLICATIONS 574 CITATIONS

SEE PROFILE 


\title{
Active control implementation in cable-stayed bridges for quasi-static loading patterns
}

\author{
Miquel Crusells-Gironaa ${ }^{\mathrm{a}, *}$, Ángel C. Aparicio ${ }^{\mathrm{b}}$ \\ ${ }^{a}$ Department of Civil and Environmental Engineering. University of California at \\ Berkeley. USA. \\ ${ }^{b}$ Department of Construction Engineering. Universitat Politècnica de Catalunya. Spain.
}

\begin{abstract}
The following paper deals with active control implementation in cable-stayed bridges. Recent developments in structural active control of cable-stayed bridges are focused on the adaptability to dynamic effects produced by earthquakes or extreme winds (El Ouni et al., 2012; Pakos and Wójcicki, 2014; Domaneschi et al., 2015a,b). Nevertheless, no attention has been paid to the static or quasi-static case. As stated by Housner et al. (1996), Song et al. (2006) or Gilewski and Al Sabouni-Zawadzka (2015), active control could also be useful to diminish fatigue in the day-to-day performance of this type of bridges by decreasing stresses adaptively. Indeed, the following paper shows that excitation periods produced by traffic loads and natural periods of vibration of this type of bridges are sufficiently distant one another so as to conclude that a quasi-static analysis can be performed. Filling this gap, the following paper proposes a structural analysis procedure to include active control systems in the design process of cable-stayed bridges, as well as suggestions which ought to be considered in order to include these cases into codes. The results of the paper, studying both non-cumulative and cumulative load cases, show a reduction in unbalanced bending moment referred to the Neutral Moment State of around $25 \%$, depending on the load case. As a result, active control systems compensating quasi-static loading patterns can certainly help engineers optimize the design of these emblematic structures.
\end{abstract}

Keywords: active control, cable-stayed bridges, long-span bridges,

\footnotetext{
${ }^{*}$ Corresponding author

Email addresses: miquel.crusells@berkeley.edu (Miquel Crusells-Girona), angel. carlos.aparicio@upc.edu (Ángel C. Aparicio)
} 
quasi-static analysis

\section{Introduction}

Cable-stayed bridges, used in long spans since the 1970s, have been gathering significant interest in the recent years. Virlogeux (1999) shows the rapid development of this type of bridges during the second half of the 20th century.

Cable-stayed bridges are bridges supported by a set of straight cables connecting the deck to the pylons in a balanced multispan arrangement (Gimsing and Georgakis, 2012, Chap. 3). The sizing and geometry optimization of these bridges was thoroughly analyzed by Simoes and Negrao (1994). Besides these orthodox designs, some heterodox designs can also be found, such as the Alamillo bridge (Aparicio and Casas, 1997). In these cases, the pylon is inclined so as to compensate dead loads with its own weight. Also, more modern designs have been proposed in the early 2000s, like under-deck single-span (Ruiz-Teran and Aparicio, 2008a) and multispan (Ruiz-Teran and Aparicio, 2008b) cable-stayed bridges.

The idea of active control of a structural response was first introduced by Kobori and Minai (1960), and was adopted in Bridge Engineering in the 1980s (Yang and Giannopoulos, 1979; Abdel-Rohman and Nayfeth, 1987). In historic concordance, when cable-stayed bridges started to be used in very long spans (Virlogeux, 1999), active control was considered to improve the behaviour of these bridges against earthquakes and extreme winds. Several theoretical (Ostenfeld and Larsen, 1992; Kawashima et al., 1993; Yang et al., 1995; Magaña et al., 1999; Rodellar et al., 2002) and experimental (Bossens and Preumont, 2001; Fujino, 2002) studies for these cases were rapidly proposed. The appearance of more modern devices (Song et al., 2006; Wang et al., 2014) and algorithms (Korkmaz, 2011; Lardies and Ta, 2011) improved significantly these active systems in the early 2000s. In recent years, researchers have been using detailed bridge models to analyse active control in the same dynamic scenarios (Bleicher et al., 2011; El Ouni et al., 2012; Pakos and Wójcicki, 2014; Domaneschi et al., 2015a,b). Nonetheless, no attention has been paid to the static or quasi-static analysis.

As a completely new approach to the topic, the authors propose to use active control also with quasi-static loading patterns, merging the classical ideas by Housner et al. (1996) with the modern ideas by Gilewski and Al Sabouni-Zawadzka (2015). 
According to the following study, one can show that, for traffic loads and cable-stayed road bridges, the excitation periods and the natural periods of vibration are significantly distant one another, and thus dynamic excitations become irrelevant (Section 2). As a consequence, the present paper proposes a structural active control system for cable-stayed road bridges so as to decrease stresses adaptively in a quasi-static manner. The detailed algorithm based on bending moment compensation is presented with detail for the control system (Section 3). Finally, the paper tests the former developments in a cable-stayed bridge designed by the authors (Section 4), including the analysis of two load cases (non-cumulative and cumulative) where the use and absence of the control system are compared. The results of these load cases show that the bending moment distribution of the bridge can be efficiently modified, reaching a reduction in unbalanced bending moments of around 25 $\%$, depending on the load case.

Therefore, a structural active control can be applied successfully to react to quasi-static loading, with a significant unbalanced bending moment reduction. Because the bending moment distribution is adaptively modified, displacements decrease and fatigue can be reduced.

\section{A quasi-static approach to traffic loads in cable-stayed bridges}

To begin with, it is important to draw a conceptual line between static or quasi-static, and dynamic loading of cable-stayed bridges. Theoretically speaking, all real physical structures behave dynamically when subjected to loads or displacements. It's only when these loads or displacements are applied very slowly, and do not produce significant oscillations, that the inertia forces can be neglected. In this case, a quasi-static analysis can be performed (Wilson, 2010, Chap. 12), as loads and displacements can be related sufficiently accurately via a static analysis. The question that arises is what slow means in this context.

Setting aside extreme winds and earthquake excitations, which clearly provoke dynamic effects, the most relevant actions on bridges are traffic loads. Traffic theory establishes that the more dense the traffic is, the slower the velocity of the flow becomes (Homburger et al., 2007, Chap. 4). As a result, one can use three representative velocities for a cable-stayed road bridge: incity bridges (assume $50 \mathrm{~km} / \mathrm{h}$ ), medium-speed bridges (assume $75 \mathrm{~km} / \mathrm{h}$ ) and highways (assume $100 \mathrm{~km} / \mathrm{h}$ ). Table 1 shows the traffic excitation periods, $T$, 
for these velocities, $v$, and for several cable-stayed bridge spans, $L$, according to the simplest approximation $T=L / v$ (Chopra, 2012, Example 3.4).

\begin{tabular}{|c|c|c|c|c|}
\hline $\mathbf{v} \mid \mathbf{L}$ & $150 \mathrm{~m}$ & $300 \mathrm{~m}$ & $400 \mathrm{~m}$ & $500 \mathrm{~m}$ \\
\hline $50 \mathrm{~km} / \mathrm{h}$ & $10.8 \mathrm{~s}$ & $21.6 \mathrm{~s}$ & $28.8 \mathrm{~s}$ & $36 \mathrm{~s}$ \\
\hline $75 \mathrm{~km} / \mathrm{h}$ & $7.2 \mathrm{~s}$ & $14.4 \mathrm{~s}$ & $19.2 \mathrm{~s}$ & $24 \mathrm{~s}$ \\
\hline $100 \mathrm{~km} / \mathrm{h}$ & $5.4 \mathrm{~s}$ & $10.8 \mathrm{~s}$ & $14.4 \mathrm{~s}$ & $18 \mathrm{~s}$ \\
\hline
\end{tabular}

Table 1: Excitation period $T$ for traffic loads and a combination of speed $v$ and span $L$.

Therefore, one wants to judge whether these excitation periods are capable of generating significant oscillations. Two types of analysis procedures are typically adopted to verify vibration behaviour due to traffic loads (Camara et al., 2014): deflection-based and acceleration-based methods. The most common one (deflection-based) follows the ideas by Smith (1988), which assume that the response is governed by the first period of vibration. Therefore, one has to establish how distant the excitation periods are to the first natural period of vibration.

Camara (2011), Chapter 4, studies the first two natural periods of vibration for two different cable assemblies. This analysis compares the experimental data obtained by Kawashima et al. (1993) with two finite-element models. Camara (2011) concludes that, if $T$ is the period in seconds and $L$, the span in meters, an accurate approximation for the first mode of vibration for a Lateral Cable Arrangement (LCP) is:

$$
T_{L C P}=0.088 L^{0.592}[\mathrm{~s}]
$$

And that an accurate approximation for the first mode of vibration for a Central Cable Arrangement (CCP) is:

$$
T_{C C P}=0.08 L^{0.583}[\mathrm{~s}]
$$

Table 2 shows the approximated natural periods of these two cable arrangements and the spans considered in Table 1.

From these figures, it is readily seen that natural periods of vibration are significantly smaller than their correspondent excitations, thus if one defines the frequency ratio $f_{r}=\frac{w}{w_{n}}$, and recalling that $w=\frac{2 \pi}{T}$, one can use the approximation $f_{r} \approx 0$. As studied by Chopra (2012), Figures 3.2.6 and 3.5.1, 


\begin{tabular}{|c|c|c|c|c|}
\hline $\mathbf{L}$ & $150 \mathrm{~m}$ & $300 \mathrm{~m}$ & $400 \mathrm{~m}$ & $500 \mathrm{~m}$ \\
\hline $\mathrm{LCP}$ & $1.7 \mathrm{~s}$ & $2.6 \mathrm{~s}$ & $3.1 \mathrm{~s}$ & $3.5 \mathrm{~s}$ \\
\hline $\mathrm{CCP}$ & $1.5 \mathrm{~s}$ & $2.2 \mathrm{~s}$ & $2.6 \mathrm{~s}$ & $3.0 \mathrm{~s}$ \\
\hline
\end{tabular}

Table 2: Approximated natural periods of vibration for LCP and CCP arrangements, and span $L$.

for harmonic excitations it is concluded that the transmissibility $T R \rightarrow 1$ and the deformation response factor $\frac{u_{0}}{\left(u_{s t}\right)_{0}} \rightarrow 1$ when $f_{r} \rightarrow 0$. Therefore, the response of the structure can be statically approximated.

In conclusion, traffic loads do not produce significant oscillations, and can thus be considered with a quasi-static approach. However, it is important to note that this fact need not mean that there are no variables that depend on time (Gosz, 2005), as there will exist registers of data that will have to be processed by the system. Instead, a quasi-static structural analysis guarantees that this time dependency can be decoupled from the structural response.

It is also relevant to note that Camara (2011)'s expressions are for vertical modes of vibration. Often, transversal modes have longer periods for long spans and shorter periods for short spans (Camara, 2011). Nevertheless, these modes are typically not excited in straight cable-stayed bridges.

As a matter of fact, a new way of taking advantage of structural active control in cable-stayed bridges arises from the precedent discussion. Indeed, an appropriate active control system can be introduced to reduce bridge stresses and displacements for traffic loads, which represent the main source of fatigue.

\section{Proposal of an active control system in quasi-static analysis}

To begin with, one has to clearly identify the control objective of the system. In the proposed case, the main goal of the active control system is to monitor the deformation of the bridge and react adaptively. As a result, stresses and displacements will also be decreased adaptively, and hence fatigue will be reduced.

Consequently, the system will need to obtain data from the structure, process it logically and actuate a mechanical system to reduce some targeted stresses. The most natural way to induce a change in the stresses in a cablestayed bridge is by means of the cables (Magaña et al., 1999; Rodellar et al., 
2002; Pakos and Wójcicki, 2014; Camara et al., 2014; Domaneschi et al., 2015a). This procedure was experimentally verified for the dynamic case by Bossens and Preumont (2001). In this study, Bossens and Preumont (2001) use a large-scale mock-up bridge model equipped with hydraulic actuators in order to demonstrate the control of the parametric vibration due to deck vibration. To this end, the paper is focused on the root locations of the transfer function, and constitutes an experimental framework for the present analysis.

The idealized system consists of a closed-loop active control system as shown in Figure 1, where $i$ is a point in the bridge deck where a cable is anchored, $M_{i}$ represents the reference bending moment that is to be achieved by the system at point $i, M_{i}^{m}$ is the bending moment measured at point $i$, $q_{i}$ is the axial force of the cable anchored at point $i$ and $e_{i}$ is the error between the reference bending moment and the real bending moment in the structure. It is important to note that this set-up only allows measuring points to be located where cables anchor to the deck. This hypothesis will provide simplifications in the gain calculations, as will be illustrated in further sections.

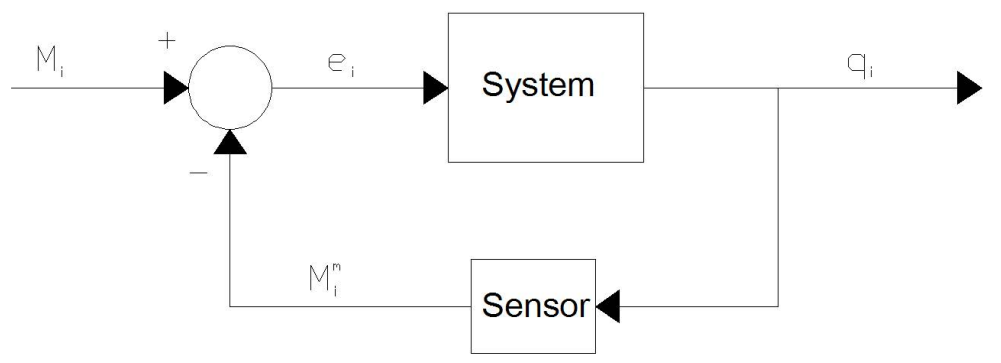

Figure 1: Closed-loop system considered for the active control.

\subsection{Measurements and obtention of bending moment values}

While it is especially difficult to measure bending moments directly from a structure, there is a well-known set of devices that can measure displacements. Because of this fact, it is chosen to measure the displacements at $m$ points. Owing to the latest developments in measuring devices, optical fiber devices are to be used. Significant work has been done in the area of structural monitoring for the latter. Particularly, the chosen devices are the 
SOFO optical fiber sensors, according to the French acronym Surveillance d'Ouvrages par Fibres Optiques, which were analysed in depth by Vurpillot et al. (1996) and Inaudi et al. (1997). In these papers, the authors establish the mathematical foundations of the measurements, and make a comparison between embedded and surface mounted arrangements. For the proposed case, surface mounted SOFO devices are preferred for practical reasons. Embedded arrangements would be very difficult, namely impossible by non-destructive methods, to access in case of malfunctioning or calibration.

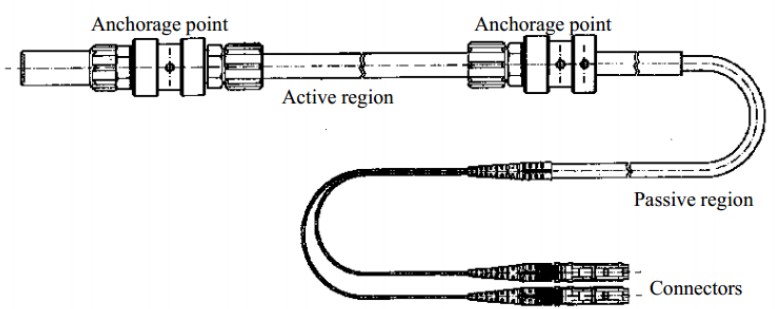

Figure 2: SOFO sensor considered in the proposed active control system, extracted from Inaudi et al. (1997).

Figure 2 shows a typical SOFO device to be used in the proposed active control system. These optical fiber sensors consist of an active zone, i.e. a measuring zone, that can go from $20 \mathrm{~cm}$ to $15 \mathrm{~m}$, depending on the use; two anchorage points that fix the device to the structure, and a passive region, whose objective is to trasmit the signals. The measuring zone is protected by a PVC cladding and contains two fibers, one that is intimatelly joined to the cladding, and therefore to the structure, and another that is free. The first fiber is used to measure the deformation of the sensor, while the second one is used for temperature adjustments. As a consequence, the easiest manner to set up the zero-displacement state is to install the devices once the structural components have been built, as zero displacements are expected for dead loads in the design of cable-stayed bridges (Gimsing and Georgakis, 2012). Therefore, the system will be allowed to take measurements for live loads without interference. The sensors proposed can also be adjusted for dynamic measures, if necessary.

Certainly, what the system is interested in are the bending moments to which the bridge is subjected. From Euler-Bernoulli beam theory, it is wellknown that the moment and the displacement in a beam can be related via 
the elastic equation. If $M(x)$ is the moment and $y(x)$, the vertical displacement of the beam, the elastic equation applies pointwise:

$$
M(x)=E I(x) \frac{d^{2} y}{d x^{2}}(x)
$$

It is important to make sure that Equation 3 holds true in the quasistatic case. Indeed, bridge design assures that a bridge has to work within the elastic range for the most probable load combinations, where traffic loads are included. Equation 3 would definitely not hold in the case of extreme loads such as earthquakes, as some plastic deformations would certainly be allowed. Also, it is interesting to note that the elastic stiffness of the girder $E I(x)$ is considered as a function of $x$, hence allowing a general cross section development for the bridge, as may be the case in variable-inertia designs.

From a numerical standpoint, the best linear approximation for the second derivative is obtained by considering three consecutive measure points $i-1$, $i$ and $i+1$, with spacing $h$ (LeVeque, 2007), as:

$$
\ddot{y}_{i}=\frac{d^{2} y}{d x^{2}}\left(x_{i}\right) \approx \frac{y_{i+1}-2 y_{i}+y_{i-1}}{h^{2}}
$$

As a result, if $n$ moment values are needed, the number of measuring points can be $n, n+1$ or $n+2$, depending on the restrictions for the displacements $y$. For instance, if there is one restriction in the displacement at node $i+1$, for which $y_{i+1}=0$, then the former equation will be a function of only two displacements, $y_{i}$ and $y_{i-1}$, and so one fewer measurement will be needed. In general, if there are $r$ restrictions in the displacements and $n$ bending moment values are needed, it can be shown that one needs $m=n+2-r$ measuring points.

Once the derivatives $\ddot{y}_{i}$ are numerically approximated, the bending moment values $M_{i}^{m}$ are obtained by applying:

$$
M_{i}^{m}=(E I)_{i} \ddot{y}_{i}
$$

where $E I(x)$ has to be approximated in the strip for which the measurement $i$ is representative, $(E I)_{i}$.

Consequently, measurements $y_{i}$ will conduct to values $\ddot{y}_{i}$, which, in turn, will translate into moment values $M_{i}^{m}$. The system will therefore collect a register of points $\left\{t_{i}, M_{i}^{m}\right\}$. Numerous studies have been focused on practical aspects of how to deal with such registers for the dynamic case, such as 
Carotti and Chiappulini (1999) and Bleicher et al. (2011). Typical sampling frequencies for the displacements are within the range 80-120 Hz; note, for instance, the frequency of $100 \mathrm{~Hz}$ used by Bleicher et al. (2011) for the case of a footbridge. This set of values is next filtered to eliminate any noise present. Because an accurate model of the actuator's behaviour is through a constanttime delay transfer function (Carotti and Chiappulini (1999), Bleicher et al. (2011)), it is accepted that average values ought to be used every $\Delta t$, a time increment similar to the time delay of the control system, $T_{d}$, (Section 3.3), 1-2 seconds typically.

Displacement values are therefore continuously used by the control system, every $\Delta t$, to adaptively change the axial force of the cables. Note that, because this is a continuously adaptable system, which, at the end of the day, relies on the pressure inside the actuators, there is no need for a threshold. This fact is justified by the results obtained in the theoretical - experimental comparisons by Carotti and Chiappulini (1999), Bossens and Preumont (2001) and Bleicher et al. (2011).

\subsection{Structural characterization: the Neutral Moment State (NMS)}

Once the bending moments $M_{i}^{m}$ are obtained, the system has to determine the axial force at which the active cables have to work in order to achieve the reference values $M_{i}$. Hence, the system needs to determine the following criteria:

1. The increase or decrease in each cable axial force.

2. The most efficient active cables to activate for each measuring section.

As a result, a procedure has to be designed in order for the system to respond to the latter two decisions. This decision-making process is based on what the authors call the Neutral Moment State (NMS), which defines the reference values for the bending moments. Several options can be proposed for these reference values. According to common practice in the design of cable-stayed bridges (Gimsing and Georgakis, 2012), it is assumed that the deformed configuration of the bridge has zero displacements for permanent loads. Therefore, the Neutral Moment State of the bridge can be defined by the bending moment distribution, for permanent loads, that conducts to zero displacements in the girder. Note that, for this calculation, load factors have to be taken as 1.0.

The measured moments, $M_{i}^{m}$, will thus be compared to the Neutral Moment State, and the errors will conduct to an actuation of the mechanical 
subsystem. This subsystem will transfer the proper tension to the cables in order to achieve the reference values.

Choosing the most effective cables to activate will imply constructing bending moment - axial force functions, which will give the bending moment at a point $P$ for a particular axial force in an active cable $C$. Within this framework, the effectiveness of the cable is to be measured by a gain function $g$. If $q$ is the axial force in the active cable $C$ and $M$ is the bending moment function of the deck, $g$ is defined as the slope ${ }^{1}$ :

$$
g=-\frac{d M}{d q}
$$

The system will therefore select an active cable for each section where the bending moment is measured by maximising the gain. It is important to note that, because elastic behaviour is assumed, the addition of the loading responses is valid. A manner to verify this fact is by means of the bending moment - axial force function. This procedure will be exemplified in the following section for a particular cable-stayed bridge.

Also, it is relevant to mention that a change in axial force in one cable and for one section also induces changes in bending moments in other sections. Therefore, after choosing what cable to actuate and how much, some postprocessing has to be performed. There are two main sources of bending moments interference between sections:

- Non-zero gains are different for all sections, even if the selected cable is the same.

- The unbalanced bending moment is different between sections, even if the selected cable is the same.

For these reasons, the system needs to use a correction for the gains. Indeed, should no correction be used, the control system would clearly overcompensate the bending moments. The methodology proposed for this correction is based on each of the former two sources of interference. In order to correct for the dispersion in the gains, an average gain for all sections is obtained for each selected cable $c, \bar{g}_{c}$, and the ratio between $\min _{c} \bar{g}_{c}$ over

\footnotetext{
${ }^{1}$ Note that the minus sign makes the gain positive when the moment distribution is raised.
} 
$\max _{c} \bar{g}_{c}$ is computed:

$$
r_{g}=\frac{\min _{c} \bar{g}_{c}}{\max _{c} \bar{g}_{c}}
$$

The parameter $r_{g}$ gives an idea of how different the selected cables behave in terms of bending moment compensation. Note that $r_{g}$ does not depend on time, as the gain function is independent of time.

In order to correct for the dispersion in the unbalanced bending moments, the same ratio in absolute value is obtained:

$$
r_{u m}=\frac{\min _{i} e_{i}}{\max _{i} e_{i}}
$$

where $e_{i}=M_{i}-M_{i}^{m}$ is the unbalanced (or error) bending moment for section $i$ (Section 3). Note that the parameter $r_{u m}$ gives an idea of how different the unbalanced moments are for some time $t$.

It is proposed, then, to use a composed value for the axial force in each selected cable, of the form

$$
\Delta N_{c}=r_{g} r_{u m} \min _{i} \Delta N_{c, i}
$$

where $\Delta N_{c}$ represents the change in axial force to be applied at the selected cable $c, r_{g}$ and $r_{u m}$ are the ratios defined before, and $\Delta N_{c, i}$ is the computed increment in axial force for the selected cable $c$ and section $i$.

Because of the fact that gains are calculated via a quasi-static analysis, there is no guarantee that they would actually be beneficial in a dynamic setting. For this reason, a permissive signal is introduced. The objective of this signal is to disconnect the active control system in case of excessive inertia forces, i.e. accelerations, as the structural algorithm would not be valid. The threshold for this permissive signal is taken from the Spanish code EHE-08 as $a_{c}=0.04 \mathrm{~g}$, as it represents, according to the code, the threshold from which dynamic effects need to be considered.

\subsection{Mechanical system}

As far as the mechanical system is concerned, the authors propose the use of a conventional mechanical circuit. This circuit will consist of pumps that will inject a fluid into some cylinders on demand, via control servovalves. Certainly, the design characteristics of this system will be highly dependent on the geometry and code loads for the bridge. The forthcoming section computes the typical design parameters for a particular mechanical system. 
Nevertheless, it is relevant to admit that the actuation of these cylinders will not be instantaneous. Thus the time taken by the system to implement the output needs to be studied. An accurate characterization of this phenomenon was proposed by Bleicher et al. (2011). In this study, the authors conclude that a first-order delay transfer function, $G_{a}(s)$, of the form, in Laplace space

$$
G_{a}(s)=\frac{1}{T \cdot s+1}
$$

is accurate to model the pressure response in the actuators. Then, considering a general transfer function for a dynamic system, $G_{s}(s)$, in Laplace space

$$
G(s)=\frac{s}{s^{2}+2 \zeta_{1} w_{1} s+w_{1}^{2}}
$$

where $w_{1}$ and $\zeta_{1}$ are the angular frequency and damping ratio of the first mode of vibration, and a delay in Laplace space, $G_{d}(s)=e^{s T_{d}}$, the equation

$$
1+G_{a}(s) G(s) G_{d}(s)=0
$$

can be used to solve for the poles, which relate $T_{d}$ and $w_{1}$. Bleicher et al. (2011) use this approach to dampen vibrations in a footbridge, hence they add an extra condition which consists of optimizing the damping ratio of the entire system, structure plus actuators. Within this framework, the authors conclude that the optimum delay time, $T_{d}$, can be obtained by

$$
T_{d}=0,86 T_{1}
$$

where $T_{1}$ is the first natural period of vibration. It is relevant, at this point, to note that, even though the structural response is considered as quasi-static, the first mode of vibration is relevant for the time delay in the actuation of the system. As a result, the present paper proposes to use the same methodology, as an optimized vibration damping goes in favour of the quasi-static analysis considered herein.

A flowchart of how all the variables relate to each other for a particular time $t_{i}$ in the structural control algorithm is shown in Figure 3.

\section{Case Study: Implementation of the active control system in a cable-stayed bridge}

Following the ideas developed in the former sections, an active control system is incorporated into a cable-stayed road bridge. The bridge considered, 


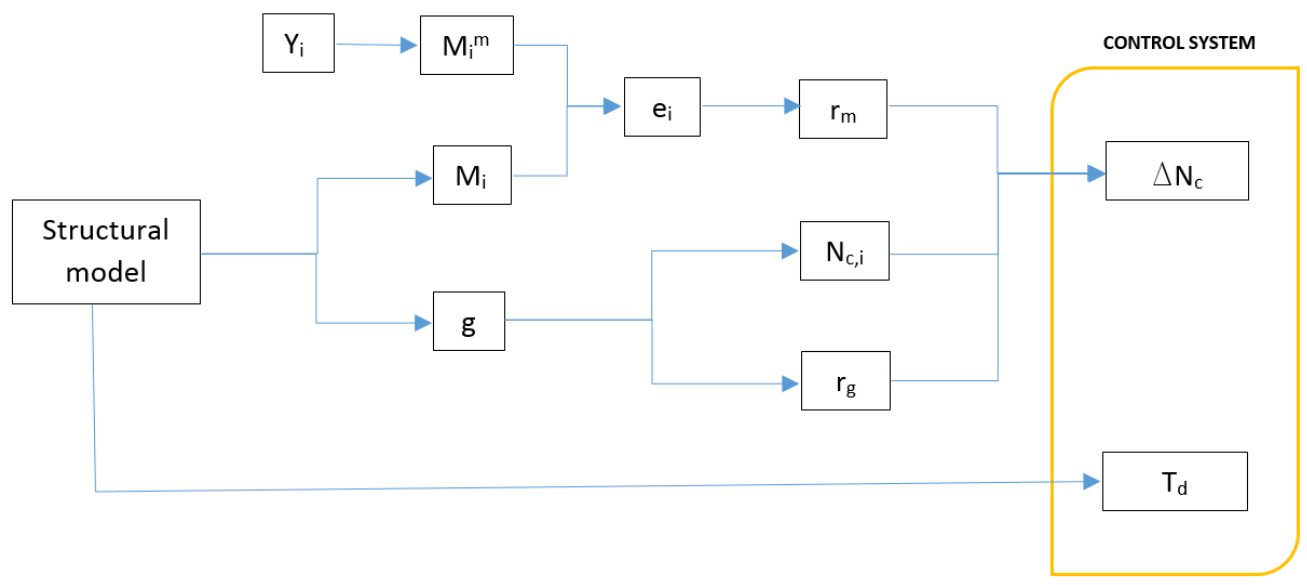

Figure 3: Flowchart of the $i$-th iteration of the structural control algorithm in terms of the variables used.

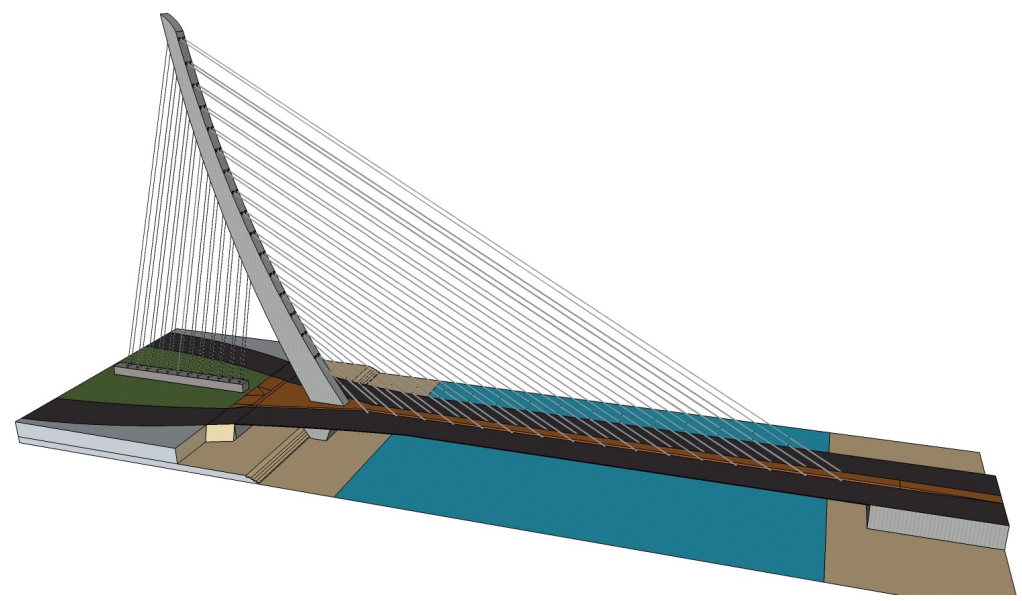

Figure 4: Designed cable-stayed bridge considered in the analysis.

Crusells-Girona (2012), was designed by the authors for academic purposes, and represents an alternative solution to the cable-stayed Alamillo bridge.

Figure 4 shows a 3D reconstruction of the bridge considered, where the left-hand side is considered as the West end, and the right-hand side is considered as the East end. This bridge consists of two spans, a lateral one of 
$27.4 \mathrm{~m}$ and a main one of $207.5 \mathrm{~m}$. The bridge is built with high-performance prestressed concrete, as it significantly decreases the susceptibility to aeroelastic effects. The detailed characteristics of the materials used are shown in Table 3.

\begin{tabular}{|c|c|c|}
\hline Material & Ultimate strength & Nomenclature \\
\hline Prestressed concrete & $75 \mathrm{MPa}$ & $\mathrm{HP}-75 / \mathrm{B} / 20 / \mathrm{IIa}$ \\
\hline Passive steel & $500 \mathrm{MPa}$ & B500S \\
\hline Active steel & $1860 \mathrm{MPa}$ & Y1860S7 \\
\hline
\end{tabular}

Table 3: Material properties and nomenclature according to the Spanish code EHE08 .

The bridge deck is solved with a prestressed symmetric tri-cellular box that accommodates 6 traffic lanes into two roads. The three cells have a width of $6.5,4.5$ and $6.5 \mathrm{~m}$, respectively, and the total width of the section is $32 \mathrm{~m}$. The two roads are separated by an elevated pedestrian zone for safety reasons. The upper concrete slab of the cross section is designed with a depth of $40 \mathrm{~cm}$, whereas the lower slab, with a depth of $35 \mathrm{~cm}$. The total depth of the section is $1.84 \mathrm{~m}$. Figure 5 shows a typical cross section of the deck, and Figure 6 illustrates the passive and active reinforcement of the cross section.

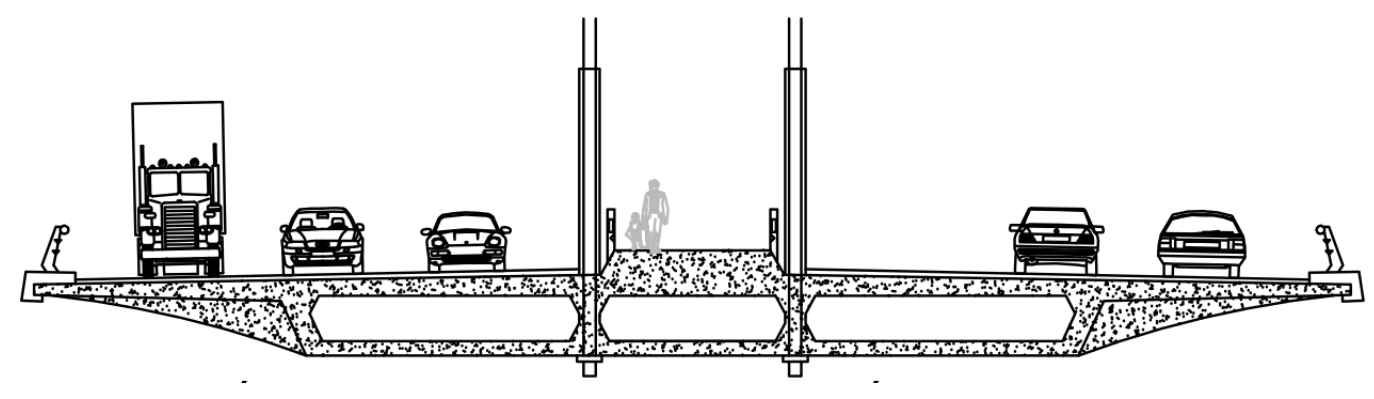

Figure 5: Typical cross section of the deck.

The pylon, clamped to the deck to minimise bending moments, describes a circumferential arch of radius $289.5 \mathrm{~m}$. Its total height from the deck reaches $150 \mathrm{~m}$. The section of the pylon is rectangular, with slab depths of $50 \mathrm{~cm}$, and varies from $14.5 \times 5.5 \mathrm{~m}$ at the bottom to $4.1 \times 4.1 \mathrm{~m}$ at the top.

The cable system consists of 16 pairs of cables in the main span, with a central cable arrangement, and 12 pairs of back stays that anchor to the 


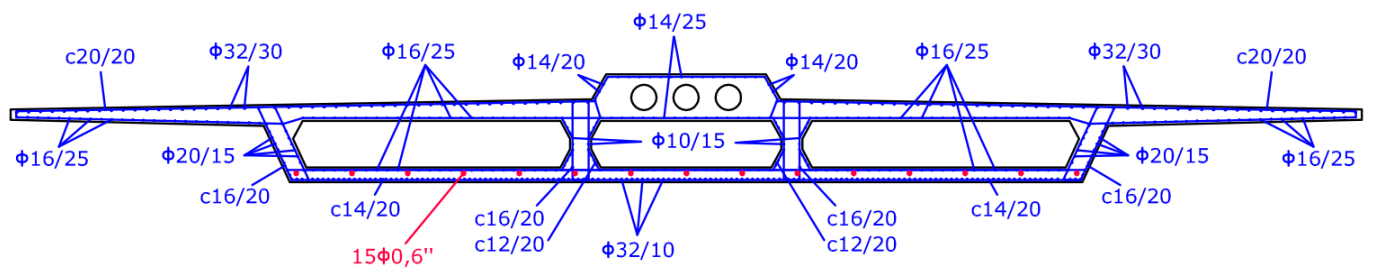

Figure 6: Active and passive reinforcement of the cross section. Diameters in mm, and spacings in $\mathrm{cm}$.

ground. The nomenclature used for the cables establishes $R$ for back stays and $T$ for stays in the main span. The numeration of the cables starts from the lowest cable, and increases to the highest one. The anchorage of the back stays to the ground is accomodated by a massive underground concrete chamber, which balances the axial forces with its own weight and permits accessibility for maintenance. A technical drawing of the structure including the nomenclature of the cables is shown in Figure 7.

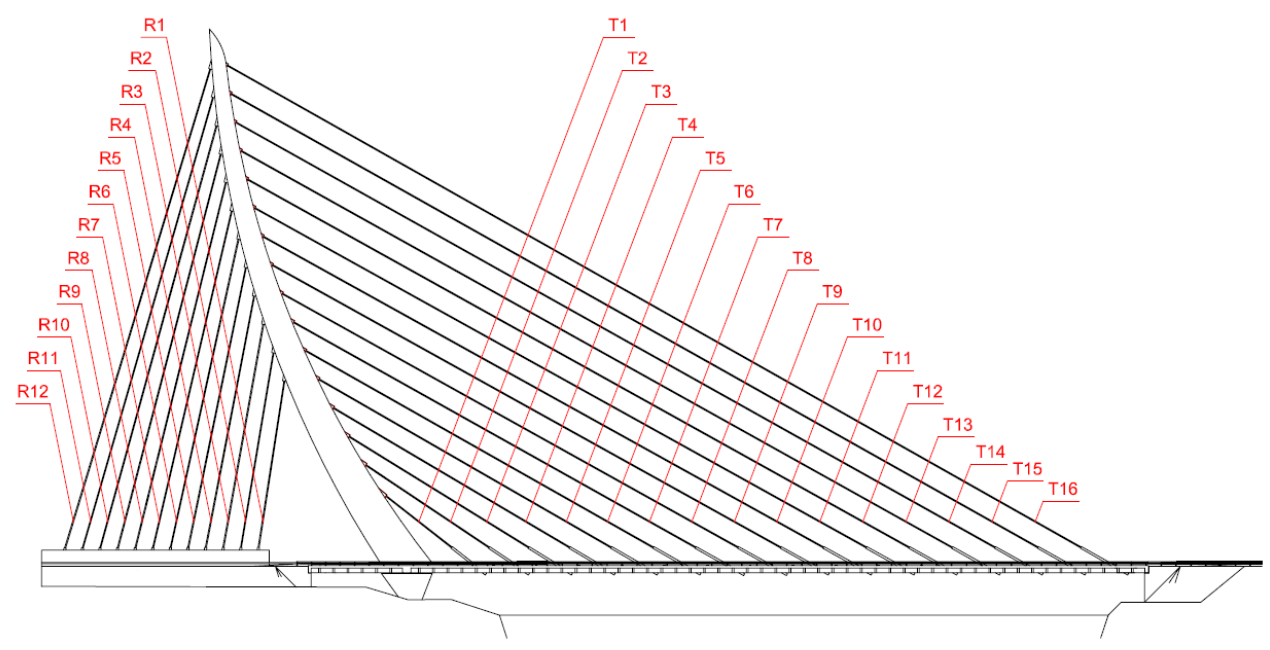

Figure 7: Technical drawing (West-East) of the designed cable-stayed bridge.

The structural design of the bridge is done according to the Spanish code EHE-08. For the structural analysis, a SAP2000 model is constructed, as shown in Figure 8. This numerical model uses linear frame elements for the 
deck and the pylon, and zero-inertia linear frame elements for the cables.

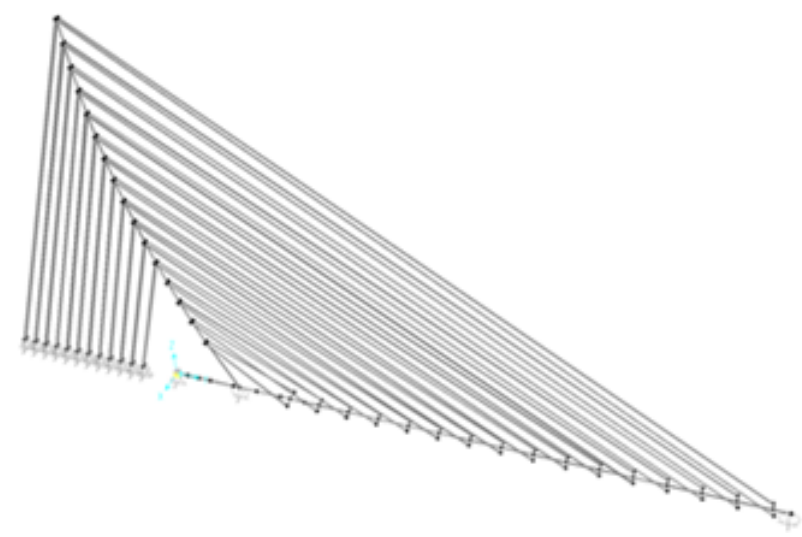

Figure 8: SAP2000 model of the designed cable-stayed bridge considered in the analysis.

The combinations of loads considered in the analysis are also in accordance with the Spanish code EHE-08. According to this code, 14 combinations of loads are analysed. These load combinations include dead loads, a code vehicle, a distributed load, wind and thermal actions. The maximum displacement obtained due to these characteristic combinations of loads is 46 $\mathrm{cm}$, which represents a deformation of L/451. Aeroelastic effects and earthquakes are also considered in the analysis, but are not relevant to the active control system exposed herein.

\subsection{Obtention of the measuring points}

As the results of the load combinations show (Crusells-Girona, 2012, Appendix 11), the main span approximately behaves as a clamped-simply supported beam, and the maximum displacements are achieved between nodes N13 and N16 (where cables T13 and T16 anchor). Therefore, the most effective area to control is precisely the area closer to the East end, where the displacements are the largest. It is decided then to use bending moment values in these precise locations of maximum deformation, four in total (N13N16). As a result, knowing that the spacing between cables is 12 meters, the control system will use $h=12$ (Section 3.1).

The required number of measuring points (Section 3.1) is $m=n+2-r=$ $4+2-1=5$, as there is one restriction $y=0$ in the East end. Consequently, 
five SOFO sensors are mounted on the surface of the lower part of the deck, where T12 to T16 are anchored.

Also, one has to determine the time delay of the system. According to Equation 13 (Section 3.3), and knowing that the first mode of vibration for the proposed bridge is excited at $T_{1}=2.6$ seconds, the delay can be computed as $T_{d}=0.86 T_{1}=2.2$ seconds. The sampling frequency is chosen to be 100 $\mathrm{Hz}$, and the values sent to the control system are defined to be the average values of every 2 seconds.

\subsection{Neutral Moment State (NMS) and active back stays}

The second step is to define the Neutral Moment State (NMS) in terms of the joint bending moments (BM). According to the former considerations, this state is the one that produces no displacements for permanent loads. The NMS is computed using the SAP2000 model, and is shown in Table 4. Sign convention considers a positive moment when it compresses the upper fibers, as usual.

\begin{tabular}{|c|c|}
\hline Section & Joint BM $(\mathbf{k N m})$ \\
\hline $\mathrm{T} 9$ & -7822 \\
\hline $\mathrm{T} 10$ & -7885 \\
\hline $\mathrm{T} 11$ & -9715 \\
\hline $\mathrm{T} 12$ & -6124 \\
\hline $\mathrm{T} 13$ & -2790 \\
\hline $\mathrm{T} 14$ & -1836 \\
\hline $\mathrm{T} 15$ & -6318 \\
\hline $\mathrm{T} 16$ & -22019 \\
\hline
\end{tabular}

Table 4: Neutral Moment State (NMS) for the proposed bridge.

The control system has to respond to two questions (Section 3.2): which cables to actuate and how much. Knowing that the zone that has to be controlled is where T13 to T16 anchor, the actuators need to be placed either controlling the T13 to T16 cables or controlling their back counterparts R9 to R12. However, a solution in which the tension in the T-cables were modified is by no means optimum in this case. Indeed, the significantly longer length of the T13-T16 cables (Figure 7) would produce significantly higher structural losses due to elastic deformation, cable bending and anchorage losses (Gimsing and Georgakis, 2012, Chapters 2,6). Moreover, there are 
practical reasons to place the actuators in the back stays, as the anchoring concrete chamber can easily accommodate maintenance duties. For these two reasons, the actuators are placed in the back stays R9 to R12, under the anchoring concrete slab. The axial forces in these cables for the NMS are shown in Table 5. It is worth pointing out that this is an initial decision, as the gain function will actually determine if some of these cables are not worth controlling.

\begin{tabular}{|c|c|}
\hline Active cable & Axial force at NMS (kN) \\
\hline R9 & 12620 \\
\hline R10 & 12947 \\
\hline R11 & 13004 \\
\hline R12 & 13009 \\
\hline
\end{tabular}

Table 5: Axial forces in the active cables for the Neutral Moment State.

As far as the change in magnitude is concerned, the gain per unit axial force is studied for each of the active cables. To this purpose, variations of the axial force are analysed. It can be inferred from the analysis that, because a quasi-static approach is adopted and plastic deformations are not allowed, the behaviour is linear. This fact will indeed be corroborated in next steps. As a result, two increments of axial force are used for simplicity. In order to establish these increments, one focuses on the bending moment variations produced by traffic loads, and chooses the increments in a representative range. In our case, it is chosen to use $\Delta N^{1}=10 k N$ and $\Delta N^{2}=30 k N$. The application of these variations into the SAP2000 model is based on the cablefreezing procedure, which consists of an equivalent temperature field. The thermal coefficient is assumed to be $1.16 \mathrm{E}-5$ for the cables (Crusells-Girona, 2012, Appendix 12). For $\Delta N^{1}=10 \mathrm{kN}$, an increment of $\Delta T^{1}=-0.27^{\circ} \mathrm{C}$ is assumed. For $\Delta N^{2}=30 k N$, an increment of $\Delta T^{2}=-0.80^{\circ} C$ is assumed.

Figure 9 illustrates the change in the NMS produced by the two increments considered for each active back stay. From these figures, the following comments must be noted:

1. The area where the bending moment distribution is raised the most is indeed the one targeted by the selection of the back stays. Indeed, moving from R9 to R12 shifts the maximum rightwards, as desired.

2. The considered response of the bridge is indeed linear in the controlled area for the proposed range of increments, as discussed. This fact can 

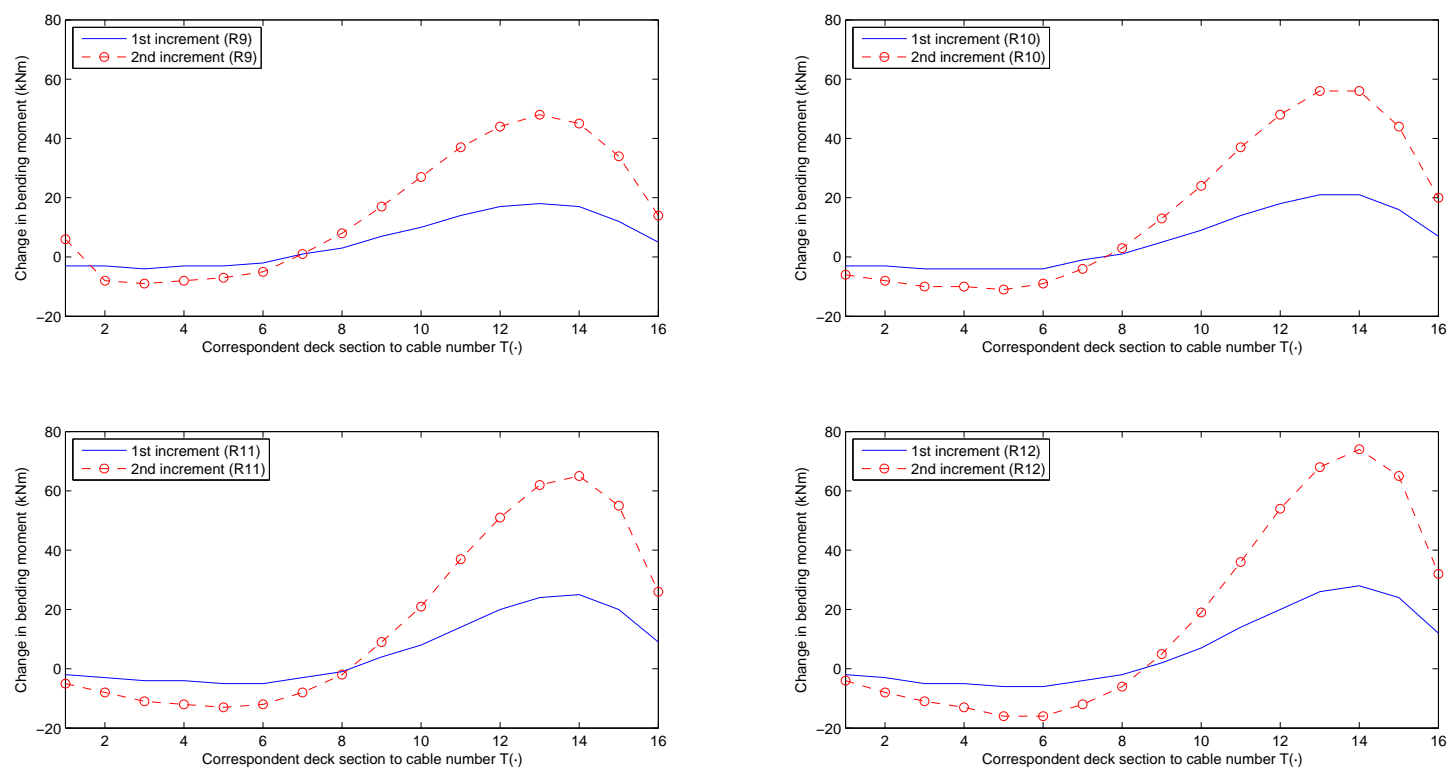

Figure 9: Change in the NMS for cables R9-R12.

be easily checked by the ratios $\Delta M / \Delta N$ at each cable node ${ }^{2}$. Note that this is, in fact, not true for the rest of the bridge deck, as the influence of the clamped tower becomes important.

3. The rise in the bending moment distribution is higher for larger $R$, i.e. larger $T$. This fact is also caused by the influence of the clamped tower.

\subsection{Bending moment - axial force gain}

In order for the system to choose the most effective cables to actuate, it is required to know how the bending moments and the axial forces are related. These relationships are constructed from Figure 9, by knowing the NMS (Table 4). Indeed, one knows the axial forces (Table 5) and bending moments for the NMS (Table 4), and how these change with the two increments for each measuring point and active back stay. Therefore, one obtains three points of the bending moment - axial force function for each measuring point and active back stay.

\footnotetext{
${ }^{2}$ See also Table 7 for further proof.
} 
As a result, the gain function (Section 3.2) for each measuring point and active back stay can be approximated by a linear interpolation of these three points. The results of these operations are shown in Table 6. Figure 10 represents the contour plot of the former values. Moreover, the regression coefficients $R^{2}$ of these linear interpolations, shown in Table 7, numerically corroborate the linear structural behaviour of the bridge.

\begin{tabular}{|c|c|c|c|c|}
\hline $\mathbf{N} \mid \mathbf{R}$ & R9 & R10 & R11 & R12 \\
\hline N9 & 0.557 & 0.429 & 0.293 & 0.164 \\
\hline N10 & 0.893 & 0.793 & 0.693 & 0.629 \\
\hline N11 & 1.221 & 1.221 & 1.221 & 1.857 \\
\hline N12 & 1.450 & 1.586 & 1.679 & 1.786 \\
\hline N13 & 1.586 & 1.850 & 2.043 & 2.243 \\
\hline N14 & 1.486 & 1.850 & 2.143 & 2.443 \\
\hline N15 & 1.129 & 1.457 & 1.821 & 2.150 \\
\hline N16 & 0.464 & 0.664 & 0.864 & 1.057 \\
\hline
\end{tabular}

Table 6: Gain produced at node $N$ due to a unit increment of the axial force at retention cable $R$ in meters.

\begin{tabular}{|c|c|c|c|c|}
\hline N|R & R9 & R10 & R11 & R12 \\
\hline N9 & 0.9922 & 0.9967 & 0.9842 & 0.9944 \\
\hline N10 & 0.9983 & 0.9978 & 0.9971 & 0.9985 \\
\hline N11 & 0.9974 & 0.9974 & 0.9974 & 0.9961 \\
\hline N12 & 0.9964 & 0.9978 & 0.9956 & 0.9983 \\
\hline N13 & 0.9978 & 0.9978 & 0.9963 & 0.9970 \\
\hline N14 & 0.9975 & 0.9978 & 0.9967 & 0.9974 \\
\hline N15 & 0.9995 & 0.9988 & 0.9988 & 0.9984 \\
\hline N16 & 0.9993 & 0.9997 & 0.9998 & 0.9978 \\
\hline
\end{tabular}

Table 7: Regression coefficients $\left(R^{2}\right)$ of the gains shown in Table 6 .

Consequently, the control system can easily determine which active back stays to actuate according to the influence of these on the structural behaviour of the bridge. Indeed, according to Figure 1, the system will determine, for a particular section, the bending moment error. Next, the system will determine, for each section, which is the most effective active cable to 


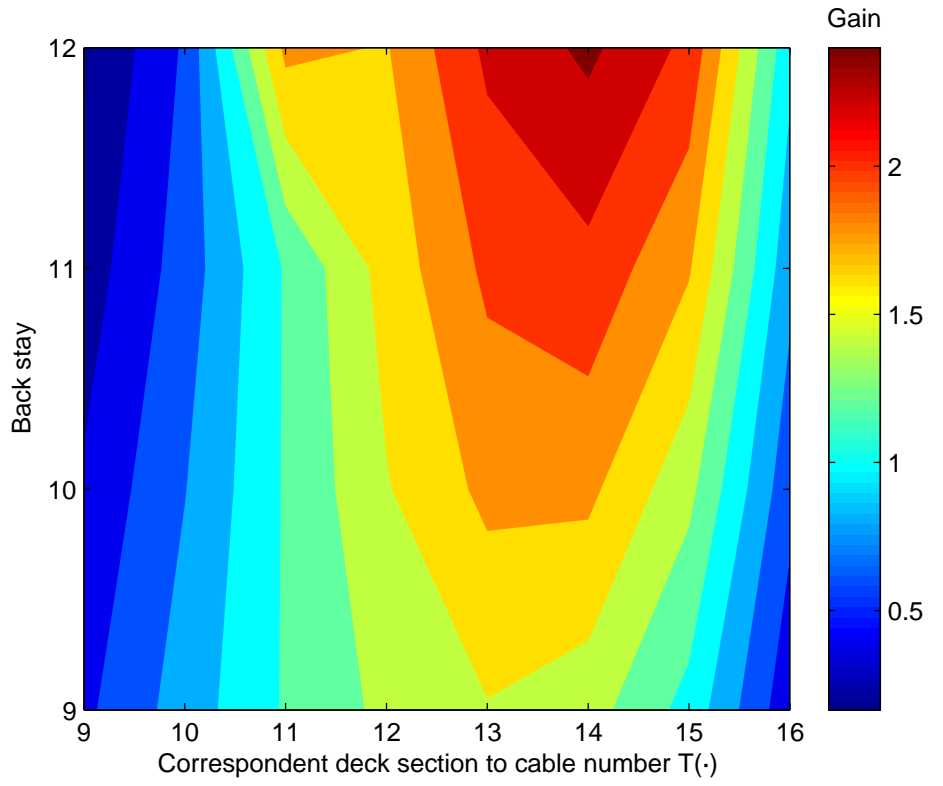

Figure 10: Contour plot for the gain produced at node $N$ due to a unit increment of the axial force at retention cable $R$ in meters.

actuate according to the gain. For example, the system is able to evaluate that, if there is a bending moment error of $-20 \mathrm{kNm}$ at node 12 , the most effective active cable to actuate is $\mathrm{R} 12(g=1.786$, the biggest), with an axial force correction of $\Delta N_{12,12}=-\Delta M / g=11.20 \mathrm{kN}$. Thus, the system has a clear ability to answer the two stated questions (Section 3.2).

The latter little example shows the procedure for deciding, for each section, what cable to actuate and how much. The system will then decide the change in axial force for each selected cable by using Equation 9, as a change in axial force in one cable and for one section also induces changes in bending moments in other sections. Indeed, the system will receive a set of average bending moment errors at time $t$, for the average time decided of 2 seconds. Then, it will decide what cables to actuate according to the former procedure. These actuations will induce changes along the bridge with a time delay $T_{d}$, which will be captured by the average bending moment errors at time $t+\Delta t$. At time $t+\Delta t$, the system will once again select, according to the procedure, what cables to actuate and how much. The same procedure will be performed at time $t+2 \Delta t, t+3 \Delta t$, etc. The flowchart in Figure 3 
shows all the steps for each time increment.

This procedure is exemplified in Section 4.5 by considering two representative load cases: a non-cumulative load case and a cumulative load case.

\subsection{Engineering design of the actuactors}

The practical engineering aspects of the design need to be addressed as well. For the proposed cable-stayed bridge, actuators are to be located in the concrete chamber of the West end. Figure 11 shows the proposed design of the actuating system.
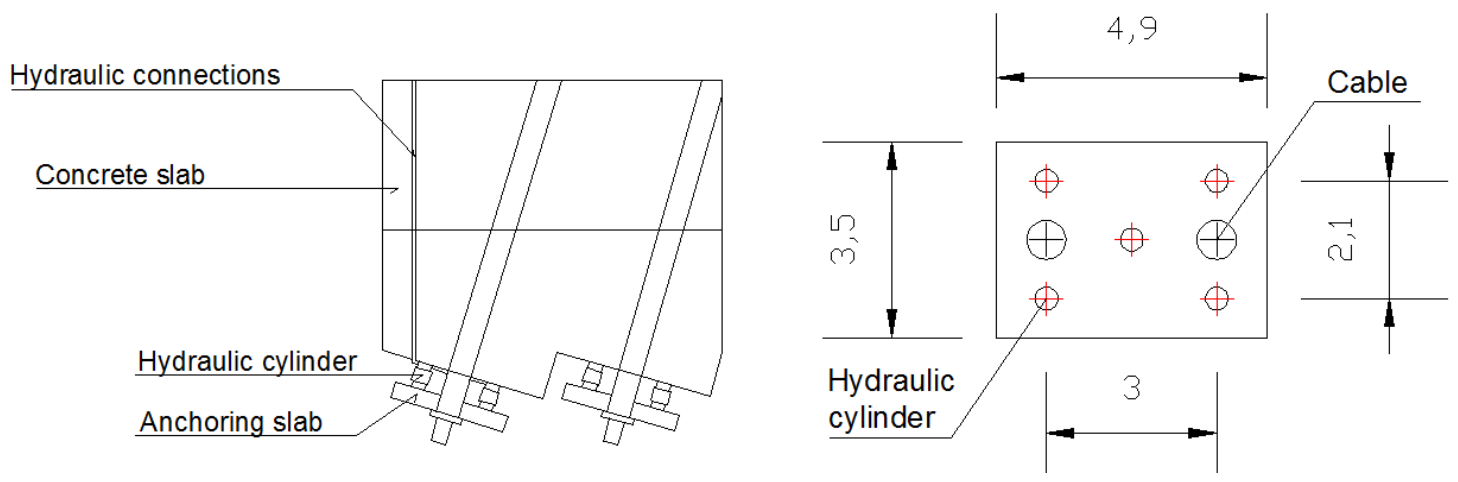

Figure 11: Engineering design of the actuating system, dimensions are in meters.

As shown in this figure, the active back stays are anchored to a small slab, which rests on the main slab thanks to five hydraulic cylinders. As a result, the change in the cable axial forces is easily performed by actuating these cylinders. Indeed, this actuation will separate the two slabs, and hence increase the axial force in the cables.

As commonly assumed in the design process of cables, the maximum allowed axial force in the cables is $0.45 f_{y k}$, being $f_{y k}$ the ultimate strength, corresponding to $\sigma_{\max }=837 \mathrm{MPa}$ (Table 3). The design characteristics of the hydraulic system are summarized in Table 8 , where $q$ represents the axial forces (nominal and required), $A$ the area (cable and cylinder), $p$ the pressure and $C$ the cylinder effective stroke.

\subsection{Load case analysis}

In order to demonstrate the advantages of the described control system for quasi-static loads, two load cases are analysed in detail for the proposed 


\begin{tabular}{|c|c|c|c|c|}
\hline Parameter & R9 & R10 & R11 & R12 \\
\hline qnom $(\mathrm{kN})$ & 12620 & 12947 & 13004 & 13009 \\
\hline $\mathrm{A}_{\text {cable }}\left(\mathrm{mm}^{2}\right)$ & 16500 & 16500 & 16500 & 16500 \\
\hline$\sigma_{\text {max }}(\mathrm{MPa})$ & 837 & 837 & 837 & 837 \\
\hline $\mathrm{q}_{\text {req }}\left(\right.$ tones $\left.^{2}\right)$ & 277 & 277 & 277 & 277 \\
\hline $\mathrm{A}_{\text {cil }}\left(\mathrm{cm}^{2}\right)$ & 695 & 695 & 695 & 695 \\
\hline $\mathrm{p}_{\text {nom }}\left(\mathrm{kg} / \mathrm{cm}^{2}\right)$ & 405 & 405 & 405 & 405 \\
\hline $\mathrm{C}(\mathrm{mm})$ & 210 & 210 & 210 & 210 \\
\hline
\end{tabular}

Table 8: Design characteristics of the hydraulic circuit.

bridge. Because it is interesting to observe the difference between a cumulative and a non-cumulative load patterns, the analysed load cases are:

- A movable load along the bridge deck, representing traffic loads passing along. This load case corresponds to a non-cumulative load pattern.

- A progressive concentration of loads on the main span of the bridge deck, representing a traffic jam. This load case corresponds to a cumulative load pattern.

\subsubsection{Movable load}

First, one considers a movable load of $100 \mathrm{kN}$ moving along the bridge deck. The velocity of this load is taken as $43.2 \mathrm{~km} / \mathrm{h}$, equivalent to one spacing between cables per second, hence producing maximum deformations on the cable sections. Time $t=0$ is assumed to be when the load is at section $T 1$. The delay time of the control system is assumed to be $T_{d}=2$ seconds, as derived. As a result, the correction in bending moments is applied after $T_{d}$. Because of the considerations in Section 2, all calculations are performed via a static analysis and using the SAP2000 model shown in Figure 8.

Table 9 shows the joint bending moments without the use of the control system, whereas Table 10 shows the same values when the control system is used.

In order to compare Tables 9 and 10, the average error of all sections, with control, $\bar{e}^{c}$, is presented in relation to the average error of all sections, without control, $\bar{e}^{w c}$, in percentage and preserving the signs as:

$$
\rho=\frac{\bar{e}^{c}-\bar{e}^{w c}}{\left|\bar{e}^{w c}\right|} * 100
$$




\begin{tabular}{|c|c|c|c|c|c|c|c|c|}
\hline Section & $\mathrm{t}=0$ & $\mathrm{t}=2$ & $\mathrm{t}=4$ & $\mathrm{t}=6$ & $\mathrm{t}=8$ & $\mathrm{t}=10$ & $\mathrm{t}=12$ & $\mathrm{t}=14$ \\
\hline $\mathrm{T} 9$ & -7764 & -7795 & -7731 & -7753 & -7737 & -7723 & -7777 & -7792 \\
\hline $\mathrm{T} 10$ & -7819 & -7823 & -7704 & -7789 & -7826 & -7780 & -7832 & -7832 \\
\hline $\mathrm{T} 11$ & -9602 & -9686 & -9604 & -9648 & -9640 & -9651 & -9617 & -9675 \\
\hline $\mathrm{T} 12$ & -6005 & -6062 & -5989 & -6051 & -6091 & -6075 & -6071 & -6099 \\
\hline $\mathrm{T} 13$ & -2717 & -2721 & -2644 & -2743 & -2752 & -2761 & -2729 & -2753 \\
\hline $\mathrm{T} 14$ & -1761 & -1791 & -1756 & -1783 & -1798 & -1777 & -1801 & -1798 \\
\hline $\mathrm{T} 15$ & -6177 & -6241 & -6201 & -6169 & -6249 & -6193 & -6255 & -6120 \\
\hline $\mathrm{T} 16$ & -21887 & -21892 & -21859 & -21845 & -21907 & -21919 & -21869 & -21910 \\
\hline
\end{tabular}

Table 9: Joint bending moments $(\mathrm{kNm})$ obtained without the use of the control system for the movable load.

\begin{tabular}{|c|c|c|c|c|c|c|c|c|}
\hline Section & $\mathrm{t}=0$ & $\mathrm{t}=2$ & $\mathrm{t}=4$ & $\mathrm{t}=6$ & $\mathrm{t}=8$ & $\mathrm{t}=10$ & $\mathrm{t}=12$ & $\mathrm{t}=14$ \\
\hline $\mathrm{T} 9$ & -7764 & -7809 & -7732 & -7783 & -7749 & -7726 & -7784 & -7794 \\
\hline $\mathrm{T} 10$ & -7819 & -7848 & -7705 & -7840 & -7841 & -7786 & -7843 & -7836 \\
\hline $\mathrm{T} 11$ & -9602 & -9729 & -9605 & -9728 & -9648 & -9660 & -9632 & -9681 \\
\hline $\mathrm{T} 12$ & -6005 & -6109 & -5991 & -6142 & -6106 & -6085 & -6088 & -6106 \\
\hline $\mathrm{T} 13$ & -2717 & -2776 & -2646 & -2845 & -2764 & -2773 & -2748 & -2761 \\
\hline $\mathrm{T} 14$ & -1761 & -1845 & -1758 & -1882 & -1805 & -1788 & -1819 & -1805 \\
\hline $\mathrm{T} 15$ & -6177 & -6285 & -6202 & -6247 & -6251 & -6202 & -6269 & -6126 \\
\hline $\mathrm{T} 16$ & -21887 & -21912 & -21859 & -21879 & -21906 & -21923 & -21875 & -21912 \\
\hline
\end{tabular}

Table 10: Joint bending moments $(\mathrm{kNm})$ obtained with the use of the control system for the movable load.

The results for $\rho$ are shown in Table 11. Note that $\rho$ at time $t=0$ is zero because of the time delay $T_{d}$. These results represent an average reduction in unbalanced bending moment along time of $27.1 \%$. Also, for this case, representative of a non-cumulative load pattern, one sees that the dispersion in $\rho$ is relevant.

Finally, the time evolution of the axial forces in the controlled cables is shown in Figure 12. This figure shows that, according to the gain values in Table 6, cables R10 and R11 are never selected to be controlled as their gain 


\begin{tabular}{|c|c|c|c|c|c|c|c|c|}
\hline Time & $\mathrm{t}=0$ & $\mathrm{t}=2$ & $\mathrm{t}=4$ & $\mathrm{t}=6$ & $\mathrm{t}=8$ & $\mathrm{t}=10$ & $\mathrm{t}=12$ & $\mathrm{t}=14$ \\
\hline$\rho(\%)$ & 0 & 60.5 & 1.0 & 77.6 & 13.7 & 10.3 & 18.8 & 8.1 \\
\hline
\end{tabular}

Table 11: Average error with control in relation to average error without control, in percentage, for the movable load.

is never optimum. As a consequence, it is possible at this point to justify that control cylinders need not be installed in these cables, according to this load case.

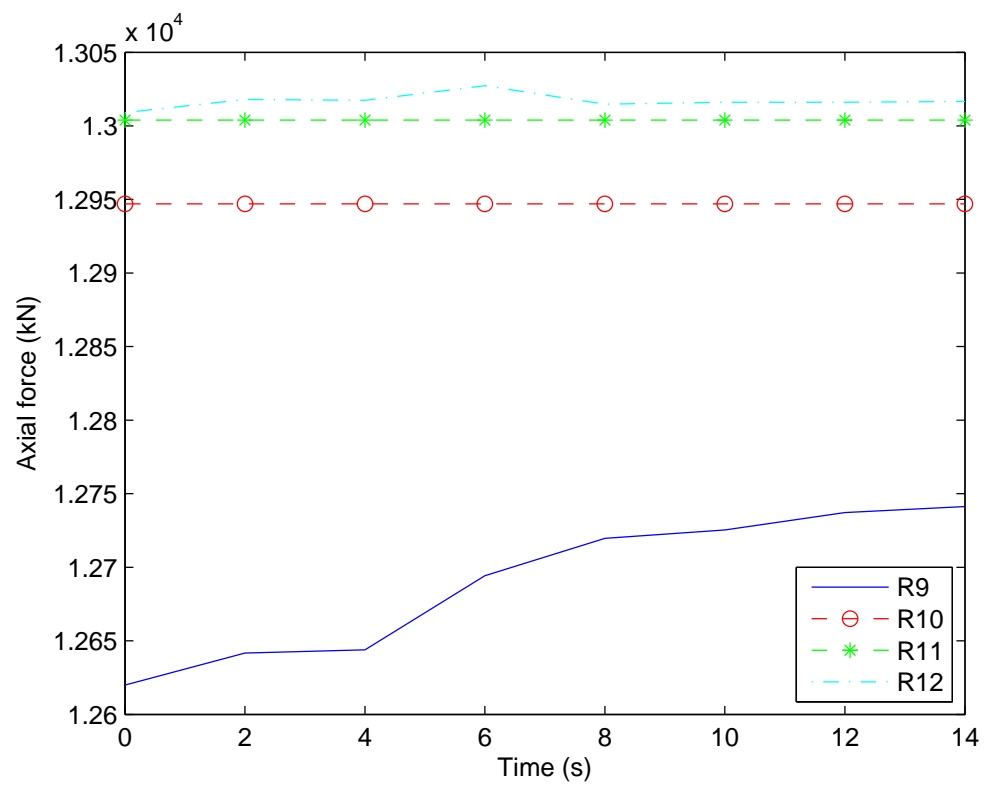

Figure 12: Evolution of axial force in controlled cables for the movable load.

Also, one sees from Figure 12 that cable R9, which has the smallest beginning axial force, is the one that suffers the most significant change, which is a desirable output according to cable design criteria.

\subsubsection{Concentration of loads}

Secondly, let us consider the use of the control system on a potential cumulative load pattern on the bridge. This situation is modelled by a pro- 
gressive accumulation of loads on the right-hand side of the bridge, where the bending moments are the largest: the first load $(100 \mathrm{kN})$ stops at section T16, the next one $(100 \mathrm{kN})$ stops at section T15, etc. The time delay between the appearance of the loads is taken equal to the time delay $T_{d}$ of the actuation system. This process is considered during 16 seconds. Time $t=0$ is assumed when the first load arrives at section T16. As a result, the correction in bending moments is applied after $T_{d}$ seconds, as before. Also, all calculations are performed via a static analysis and using the SAP2000 model shown in Figure 8.

Table 12 shows the joint bending moments without the use of the control system, whereas Table 13 shows the same values when the control system is used.

\begin{tabular}{|c|c|c|c|c|c|c|c|c|}
\hline Section & $\mathrm{t}=0$ & $\mathrm{t}=2$ & $\mathrm{t}=4$ & $\mathrm{t}=6$ & $\mathrm{t}=8$ & $\mathrm{t}=10$ & $\mathrm{t}=12$ & $\mathrm{t}=14$ \\
\hline T9 & -7720 & -7694 & -7656 & -7711 & -7687 & -7691 & -7761 & -7775 \\
\hline T10 & -7799 & -7694 & -7698 & -7816 & -7744 & -7665 & -7786 & -7852 \\
\hline T11 & -9640 & -9632 & -9551 & -9582 & -9541 & -9540 & -9608 & -9641 \\
\hline T12 & -6058 & -6035 & -5931 & -6075 & -6058 & -5996 & -6100 & -6103 \\
\hline T13 & -2758 & -2675 & -2671 & -2724 & -2598 & -2669 & -2699 & -2763 \\
\hline T14 & -1783 & -1763 & -1695 & -1781 & -1713 & -1681 & -1749 & -1803 \\
\hline T15 & -6244 & -6097 & -6042 & -6149 & -6135 & -6216 & -6239 & -6255 \\
\hline T16 & -21853 & -21876 & -21606 & -21871 & -21862 & -21869 & -21871 & -21936 \\
\hline
\end{tabular}

Table 12: Joint bending moments $(\mathrm{kNm})$ obtained without the use of the control system for the traffic jam.

As before, in order to compare Tables 12 and 13, the average error of all sections, with control, $\bar{e}^{c}$, is presented in relation to the average error of all sections, without control, $\bar{e}^{w c}$, in percentage (Section 4.5.1). The results are shown in Table 14. In this case, these results represent an average reduction in unbalanced bending moment along time of $22.8 \%$. In this case, representative of a cumulative load pattern, one sees that the dispersion in $\rho$ is less relevant than in the former case.

Finally, the time evolution of the axial forces in the controlled cables is shown in Figure 13. Once again, one realizes that cables R10 and R11 are never selected to be controlled as their gain is never optimum. As a 


\begin{tabular}{|c|c|c|c|c|c|c|c|c|}
\hline Section & $\mathrm{t}=0$ & $\mathrm{t}=2$ & $\mathrm{t}=4$ & $\mathrm{t}=6$ & $\mathrm{t}=8$ & $\mathrm{t}=10$ & $\mathrm{t}=12$ & $\mathrm{t}=14$ \\
\hline $\mathrm{T} 9$ & -7720 & -7701 & -7670 & -7725 & -7688 & -7713 & -7779 & -7780 \\
\hline $\mathrm{T} 10$ & -7799 & -7759 & -7722 & -7840 & -7746 & -7703 & -7816 & -7860 \\
\hline $\mathrm{T} 11$ & -9640 & -9652 & -9587 & -9619 & -9544 & -9600 & -9649 & -9650 \\
\hline $\mathrm{T} 12$ & -6058 & -6058 & -5972 & -6117 & -6062 & -6064 & -6148 & -6114 \\
\hline $\mathrm{T} 13$ & -2758 & -2700 & -2717 & -2771 & -2602 & -2745 & -2752 & -2775 \\
\hline $\mathrm{T} 14$ & -1783 & -1787 & -1739 & -1827 & -1717 & -1755 & -1798 & -1813 \\
\hline $\mathrm{T} 15$ & -6244 & -6116 & -6077 & -6185 & -6138 & -6275 & -6277 & -6262 \\
\hline $\mathrm{T} 16$ & -21853 & -21884 & -21621 & -21887 & -21863 & -21895 & -21887 & -21939 \\
\hline
\end{tabular}

Table 13: Joint bending moments $(\mathrm{kNm})$ obtained with the use of the control system for the traffic jam.

\begin{tabular}{|c|c|c|c|c|c|c|c|c|}
\hline Time & $\mathrm{t}=0$ & $\mathrm{t}=2$ & $\mathrm{t}=4$ & $\mathrm{t}=6$ & $\mathrm{t}=8$ & $\mathrm{t}=10$ & $\mathrm{t}=12$ & $\mathrm{t}=14$ \\
\hline$\rho(\%)$ & 0 & 14.2 & 15.3 & 32.8 & 2.0 & 35.8 & 42.0 & 17.2 \\
\hline
\end{tabular}

Table 14: Average error with control in relation to average error without control, in percentage, for the traffic jam.

consequence, it is possible at this point to justify that control cylinders need not be installed in these cables, according to this load case.

From Figure 13, and in line with the results from the movable load case (Section 4.5.1), one also observes that cable R9, which has the smallest beginning axial force, is the one that suffers the most significant change, as desired.

\section{Code considerations and risk-informed decision-making}

The most important disadvantage of structural active control is how to design against the malfunctioning of the system. A conservative position towards this situation would require to satisfy the same standards as if there were no active system, as this would be the worst-case scenario. In this case, the design of the bridge with active control would hardly differ to the one without it. The authors think this would not be a reasonable approach.

It is undeniable that serviceability cannot be put at stake by a control 


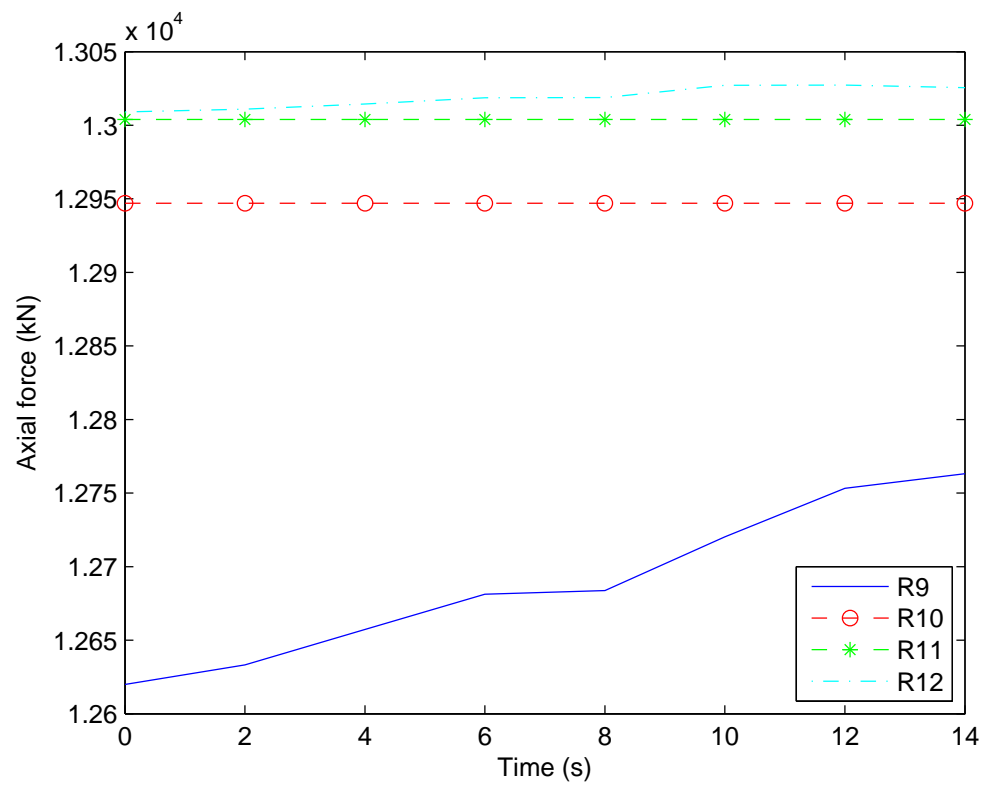

Figure 13: Evolution of axial force in controlled cables for the traffic jam.

system. Nonetheless, ultraconservatism makes the active control not beneficial. In order to overcome this duality, and according to the singularity of these systems in Bridge Engineering, the proposed method to analyse the scenario of system malfunctioning is via a risk-informed procedure.

Risk analysis and risk-informed decisions, yet not very common in Civil Engineering practice, are widely used in industrial facilities such as nuclear power plants. The idea of these procedures is to come up with a probability of malfunctioning of the system based on the failure probabilities of its components. To this end, a fault tree of the system is constructed, following the techniques described in Bedford and Cooke (2001), a reference book in probabilistic analysis.

Once the probability of failure of the system is known, it ought to be compared to a reference probability established by the code. The code should assist in a relationship between the load factors and the failure probability, so that the more probable the malfunctioning is, the closer the design should be to the non-controlled solution. 


\section{Conclusions and future developments}

In conclusion, this study provides a detailed procedure to incorporate structural active control in the design of cable-stayed bridges for quasi-static loading patterns, which had not been considered before.

First, the study concludes that natural periods of vibration for vertical modes and excitation periods of traffic loads are uncoupled in cable-stayed bridges (Section 2). This fact allows the analysis to neglect inertia forces, and permits a quasi-static analysis. As a result, a quasi-static analysis is used in the structural calculations that the control system requires.

The active control system proposed is based on the active control of the cables. Therefore, the system needs to clearly identify which cables to actuate and how much. These decisions are proposed to be based on two facts (Section 3): the Neutral Moment State (NMS), which identifies the necessary bending moments that produce zero displacements on the bridge deck for permanent loads, and the gain extracted from the bending moment - axial force functions. The former is used as a reference value, whereas the latter is used to select the most efficient cable to actuate and to decide the change in the cable axial force. The flowchart in Figure 3 provides the relationship of all the parameters used for this decision-making process at a particular time $t_{i}$.

A particular cable-stayed bridge designed by the authors (Section 4) is used to exemplify and quantify the benefit of the control system. The results of this analysis show that a cable-by-cable approach is valid due to linearity (Table 7), and so that the proposed bending moment compensation process is a useful technique to set up the structural control algorithm. It is important to note that, because a quasi-static analysis is performed, the proposed algorithm is not valid when inertia forces are significant. A permissive signal, which disconnects the control system in case of significant accelerations, is used to acknowledge this limitation.

In order to quantify the benefits of the control system, two representative load cases are analysed for the former bridge: a movable load along the deck (non-cumulative load pattern) and a progressive accumulation of loads on the right side of the main span (cumulative load pattern). For the first

case, one observes an average reduction in unbalanced bending moments of $27.1 \%$. This first case also presents a wider variability in the reduction. As far as the second case is concerned, one computes an average reduction in unbalanced bending moments of $22.8 \%$. Even though the reduction is 
smaller, the variability is reduced for the cumulative load case. Also, one observes in both cases that the back stay with smallest beginning axial force (R9 in this case) is the one suffering the most significant change in axial force, which is a desirable output according to cable design criteria. In conclusion, the results for these load cases show that there is an actual substantial benefit when using the proposed control system.

Also, probabilistic risk analysis is suggested to be included in codes in order to consider the malfunctioning of the system without overdesigning the bridge.

Regarding future developments, an interesting analysis to be performed is to study the frontier between the dynamic and the quasi-static analysis. This study would be able to merge the capabilities of the active control in both the dynamic and the quasi-static cases.

\section{Acknowledgements}

The authors would like to thank Prof. Anil K. Chopra, from the Department of Civil and Environmental Engineering at the University of California at Berkeley, for his opinions and insights on quasi-static analysis.

\section{References}

Abdel-Rohman, M., Nayfeth, A., 1987. Active control of nonlinear oscillations in bridges. Journal of Engineering Mechanics 113, 335-348.

Aparicio, A. C., Casas, J. R., 1997. The Alamillo cable-stayed bridge: special issues faced in the analysis and construction. Proceedings of the Institution of Civil Engineers (Structures and Buildings) 122 (4), 432-450.

Bedford, T., Cooke, R., 2001. Probabilistic risk analysis: foundations and methods, 1st Edition. Cambridge University Press.

Bleicher, A., Schlaich, M., Fujino, Y. Schauer, T., 2011. Model-based design and experimental validation of active vibration control for a stress ribbon bridge using pneumatic muscle actuators. Engineering Structures 33, 22372247.

Bossens, F., Preumont, A., 2001. Active tendon control of cable-stayed bridges, a large scale demonstration. Earthquake Engineering and Structural Dynamics 30, 961-979. 
Camara, A., 2011. Seismic behaviour of cable-stayed bridges: design, analysis and seismic devices. Ph.D. thesis, Technical University of Madrid, advised by Prof. Dr. Miguel Ángel Astiz Suárez. Downloadable: http://oa.upm.es/10036/.

Camara, A., Nguyen, K., Ruiz-Teran, A., Stafford, P., 2014. Serviceability limit state of vibrations in under-deck cable-stayed bridges accounting for vehicle-structure interaction. Engineering Structures 61, 61-72.

Carotti, A., Chiappulini, R., 1999. Sizing a hydromechanical servodrive for the active control of the runnability of cable-stayed bridges. trade-off between different techniques. Applied Mathematical Modelling 23, 175-198.

Chopra, A., 2012. Dynamics of structures. Theory and applications to Earthquake Engineering., 4th Edition. Prentice Hall.

Crusells-Girona, M., 2012. Alternative construction project of the Alamillo bridge. Master's thesis, Technical University of Catalonia, advised by Prof. Dr. Ángel C. Aparicio. Original in Spanish. Downloadable: http://upcommons.upc.edu/pfc/handle/2099.1/19969?locale=en.

Domaneschi, M., Martinelli, L., Perotti, F., 2015a. Wind and earthquake protection of cable-supported bridges. Proceedings of the ICE - Bridge Engineering.

Domaneschi, M., Martinelli, L., Po, E., 2015b. Control of wind buffeting vibrations in a suspension bridge by TMD: hybridization and robustness issues. Computers and Structures 155, 3-17.

EHE-08, 2008. Instrucción de Hormigón Estructural. Ministry of Public Constructions, Spanish code for Structural Concrete.

El Ouni, M., Ben Kahla, N., Preumont, A., 2012. Numerical and experimental dynamic analysis and control of a cable-stayed bridge under parametric excitation. Engineering Structures 45, 244-256.

Fujino, Y., 2002. Vibration, control and monitoring of long-span bridges recent research, developments and practice in Japan. Journal of Constructional Steel Research 58, 71-97. 
Gilewski, W., Al Sabouni-Zawadzka, A., 2015. On possible applications of smart structures controlled by self-stress. Archives of Civil and Mechanical Engineering 15, 469-478.

Gimsing, N., Georgakis, C., 2012. Cable supported bridges: concept and design, 3rd Edition. John Wiley and Sons.

Gosz, M., 2005. Finite element method: Applications in solids, structures and heat transfer. CRC Press.

Homburger, W., Hall, J., Reilly, W., Sullivan, E., 2007. Fundamentals of Traffic Engineering., 16th Edition. Institute of Transportation Studies. University of California at Berkeley.

Housner, G., Soong, T. T., Masri, S. F., 1996. Second generation of active structural control in Civil Engineering. Computer-Aided Civil and Infrastructure Engineering 11 (5), 289-296.

Inaudi, D., Casanova, N., Kronenberg, P., Marazzi, S., Vurpillot, S., 1997. Embedded and surface mounted fiber optic sensors for civil structural monitoring. In: SPIE Conference on Smart Structures and Materials. San Diego, USA.

Kawashima, K., Unjoh, S., Tunomoto, M., 1993. Estimation of damping ratio of cable-stayed bridges for seismic design. Journal of Structural Engineering 119 (4), 1015-1031.

Kobori, T., Minai, R., 1960. Analytical study on active seismic response control. Transactions of the Architectural Institute of Japan 66, 257-260.

Korkmaz, S., 2011. A review of active structural control: challenges for engineering informatics. Computers and Structures 89, 2113-2132.

Lardies, J., Ta, M., 2011. Modal parameter identification of stay cables from output-only measurements. Mechanical Systems and Signal Processing 25, $\underline{133-150 .}$

LeVeque, R., 2007. Finite difference methods for ordinary and partial differential equations. Steady state and time dependent problems. Society for Industrial and Applied Mathematics. 
Magaña, M., Rodellar, J., Casas, J., Mas, J., 1999. Active control of cablestayed bridges. In: Smart Structures. Requirements and potential applications in Mechanical and Civil Engineering. Springer Science, pp. 193-202.

Ostenfeld, K., Larsen, A., 1992. Bridge engineering and aerodynamics. In: Proceedings of the first International Symposium on Aerodynamics of large bridges. pp. 3-22.

Pakos, W., Wójcicki, Z., 2014. Vibration control of a cable-stayed footbridge using the tension changes of cable. Procedia Engineering 91, 142-147.

Rodellar, J., Mañosa, V., Monroy, C., 2002. An active tendon control scheme for cable-stayed bridges with model uncertainties and seismic excitation. Journal of Structural Control 9, 75-94.

Ruiz-Teran, A., Aparicio, A., 2008a. Structural behaviour and design criteria of under-deck cable-stayed bridges and combined cable-stayed bridges. Part I: single-span bridges. Canadian Journal of Civil Engineering 35, 938950.

Ruiz-Teran, A., Aparicio, A., 2008b. Structural behaviour and design criteria of under-deck cable-stayed bridges and combined cable-stayed bridges. Part II: multispan bridges. Canadian Journal of Civil Engineering 35, 951962.

Simoes, L., Negrao, J., 1994. Sizing and geometry optimization of cablestayed bridges. Computers and Structures 52 (2), 309-321.

Smith, J., 1988. Vibration of structures, applications in Civil Engineering design. Chapman and Hall.

Song, G., Sethi, V., Li, H., 2006. Vibration control of civil structures using piezoceramic smart materials: a review. Engineering Structures 28, 15131524 .

Virlogeux, M., 1999. Recent evolution of cable-stayed bridges. Engineering Structures 21, 737-755.

Vurpillot, S., Inaudi, D., Scano, A., 1996. Mathematical model for the determination of the vertical displacement from internal horizontal measurements of a bridge. In: SPIE Conference on Smart Structures and Materials. San Diego, USA. 
Wang, M., Lynch, J., Sohn, H., 2014. Sensor technologies for civil infrastructures. Woodhead Publishing.

Wilson, E. L., 2010. Static and dynamic analysis of structures. A physical approach with emphasis on Earthquake Engineering., 4th Edition. Computers and Structures, Inc.

Yang, J., Giannopoulos, F., 1979. Active control and stability of cable-stayed bridge. ASCE Journal of Engineering Mechanics Division 105, 677-694.

Yang, J., Wu, J., Kawashima, K., Unjoh, S., 1995. Hybrid control of seismicexcited bridge structures. Earthquake Engineering and Structural Dynamics $24,1437-1451$. 